\title{
Sorption of phenol and radioactive cesium onto surfactant modified insolubilized humic acid
}

\author{
O. Celebi $\cdot$ H. N. Erten
}

Received: 8 March 2010/Published online: 26 March 2010

(C) Akadémiai Kiadó, Budapest, Hungary 2010

\begin{abstract}
In this study, the sorption behavior of two important contaminants, phenol and radioactive cesium $\left({ }^{137} \mathrm{Cs}\right)$, onto surfactant modified insolubilized humic acid (SMIA) were investigated as a function of time, sorbate concentration utilizing the radiotracer method and UV-Vis spectroscopy. Phenol sorption process was well described by both Freundlich and Tempkin type isotherms, and cesium sorption was described by Freundlich and DubininRadushkevich isotherms. It was found that SMIA adsorbs both cations and phenolic substances. Kinetic studies indicated that adsorption behavior of phenol obey the pseudo second order rate law. FTIR spectroscopic technique was used to understand the structural changes during modification process with surfactants.
\end{abstract}

Keywords Adsorption - Phenol - Radioactive cesium . Surfactant modified insolubilized humic acid · Isotherms . Kinetic studies · UV-Vis spectrometry

\section{Introduction}

Chemical industries such as paint, pesticide, coal conversion, polymeric resin, petroleum and petrochemicals generate phenolic substances which are harmful contaminants for water sources. Contaminated water have negative

O. Celebi $(\bowtie)$

Department of Chemistry, Macromolecular Science and Engineering, Virginia Tech, Blacksburg, VA 24061, USA e-mail: celebi@vt.edu

O. Celebi · H. N. Erten

Department of Chemistry, Bilkent University, 06800 Bilkent, Ankara, Turkey effects on ecosystems and humans (toxicity, carcinogenic and mutagenic properties). Phenol is one of the most common environmental pollutants. It is highly soluble in water and toxic even at low concentrations, and also converted to its harmful derivatives such as chlorophenols etc. during disinfection and oxidation processes. Phenolic compounds cause unpleasant taste and odor of drinking water and most of these compounds are known as toxic carcinogens [1-4]. The radionuclide ${ }^{137} \mathrm{Cs}$ is produced in high yield during the fission process and due to its long halflife $\left(T_{1 / 2}=30.17 \mathrm{yr}\right)$ and its high solubility in the aqueous media, it is a principal radiocontaminant in radioactive wastes [5].

Humic acid is one of the major components of soil organic matter and has a large tendency to bind cations, because of the presence of phenolic and carboxylic functional groups. Even humic acid is considered as a good sorbent for removal of toxic cations, it has the disadvantage of being soluble above $\mathrm{pH} 2-3$ making it an inappropriate sorbent. Therefore, humic acid is converted to its insolubilized form to make it an appropriate sorbent even at alkaline conditions, utilizing insolubilization process developed by Seki and Suzuki [6]. A number of investigations have been carried out upon the sorption behavior of insolubilized humic acid to cations such as nickel, cesium, barium, copper etc. [7-14].

Adsorption is an important equilibrium separation process and an effective method for water decontamination applications. Adsorption technique has many advantages such as initial cost, flexibility and simplicity of design, ease of operation and insensitivity to toxic pollutants compared to other techniques and also it does not result in the formation of harmful substances [2]. Using insolubilized humic acid as an adsorbent is very advantageous because of its low production cost and local availability. 
The objective of present work is to modify insolubilized humic acid so that it could also adsorb harmful organic (phenolic) substances as well as toxic cations and radionuclides. Thus, we modified insolubilized humic acid with cationic surfactant (cetyltrimethylammonium chloride). Phenol and cesium sorption data onto surfactant modified insolubilized humic acid (SMIA) was analyzed using Freundlich, Dubinin-Radushkevich and Tempkin isotherms. Structural changes during surfactant modification were determined by FTIR spectroscopic technique.

\section{Experimental}

\section{Chemicals}

All chemicals used were of analytical grade. Humic acid samples originated from Nigde (Bor) region in Turkey. Distilled water was used in preparing metal ion solutions. No further ionic strength or $\mathrm{pH}$ control was attempted. The $\mathrm{pH}$ of the solutions in contact with sodium form of insolubilized humic acid (INaA) was 3.5. Phenol and cetyltrimethylammonium chloride was purchased from Merck and used as received.

Preparation of surfactant modified insolubilized humic acid

In our previous study [7], we expressed the experimental procedure for the isolation of humic acid and its conversion to sodium form of insolubilized humic acid (INaA) in detail as well as their characterization utilizing FTIR, ${ }^{13} \mathrm{C}$ solid state NMR and potentiometric titration techniques. After preparing INaA, the following procedure was followed to obtain surfactant modified insolubilized humic acid. One hundred milliliters of concentrated cetyltrimethylammonium chloride solution was placed in a flask and $5 \mathrm{~g}$ of INaA added. The dispersions were shaken at room temperature by a mechanic shaker for $60 \mathrm{~h}$, followed by washing with distilled water. SMIA was dried at $50{ }^{\circ} \mathrm{C}$ in an oven for $24 \mathrm{~h}$.

\section{Adsorption experiments}

\section{Radiotracer method}

Throughout the study, the batch method was applied. The tracer used in sorption experiments was ${ }^{137} \mathrm{Cs}\left(T_{1 / 2}=\right.$ $30.17 \mathrm{yr}$ ). One litre of stable isotope solutions were spiked with $400 \mu \mathrm{L}$ of the cesium radionuclide solution. The initial count rates were measured for $2.5 \mathrm{~mL}$ aliquots of cesium solutions using the prominent $\gamma$ rays of $662 \mathrm{keV}$.
Initial acitivity was adjusted not to be lower than $10000 \mathrm{cps} / \mathrm{mL}$.

A $\mathrm{NaI}(\mathrm{Tl})$ detector was used during radioactivity measurements of the samples. All the experiments were performed in duplicates. In order to check any loss in the activity originating from adsorption on the inside wall of tubes, blank experiments were performed using solutions without adsorbent. The results showed that adsorption onto the tube walls was negligible.

\section{Kinetic studies}

During phenol sorption studies to SMIA, in order to evaluate kinetic data, separate tubes containing $50 \mathrm{mg}$ of SMIA and $8 \mathrm{~mL}$ of $20 \mathrm{mg} \mathrm{L}^{-1}$ phenol solution were prepared. The samples were shaken at room temperature for periods ranging from 1 to $72 \mathrm{~h}$. After centrifugation, absorbance measurements of liquid phases were carried out at $270 \mathrm{~nm}$ using UV-VIS spectrophotometer. Absorbance data were converted into concentration using calibration relations pre-determined at the wavelength of maximum absorbance for each phenol sample.

In our previous study, equilibrium time for cesium sorption onto sodium form of insolubilized humic acid was found to be $5 \mathrm{~h}$. Cesium ion reaches the sorption equilibrium very quickly, therefore we have chosen $24 \mathrm{~h}$ for cesium sorption onto SMIA.

\section{Effect of loading}

Loading experiments were carried out to investigate the effect of initial cation concentrations on sorption at $25{ }^{\circ} \mathrm{C}$ and at the initial concentrations of $5 \times 10^{-4}, 1 \times 10^{-4}$, $1 \times 10^{-5}, 5 \times 10^{-6}(\mathrm{mmol} / \mathrm{mL})$ for $\mathrm{Cs}^{+}$sorption onto SMIA. Shaking was done in a temperature controlled environment using a Nuve ST 402 water bath shaker equipped with microprocessor thermostat. The fluctuation in controlled temperature was $\pm 1{ }^{\circ} \mathrm{C}$.

In the case of phenol sorption onto SMIA, at $25{ }^{\circ} \mathrm{C}$ adsorption isotherm experiment, the same amount of sorbent and sorbate (as given in the kinetic part) were used in the concentration range from 20 to $80 \mathrm{mg} \mathrm{L}^{-1}$. The solution and sorbent were separated by centrifugation and analyzed for determining the remaining concentration of phenol in solution using UV-Visible spectrophotometer at $270 \mathrm{~nm}$.

FTIR spectroscopic characterization of surfactant modified insolubilized humic acid

FT-IR spectra were recorded using a Bruker Tensor 27 FTIR spectrometer with a standard high sensitivity DLATGS detector, with a resolution of $4 \mathrm{~cm}^{-1}$ and 64 
scans, The $\mathrm{KBr}$ pellets were obtained by pressing a mixture of 1:100 ratio of humic samples and $\mathrm{KBr}$, respectively.

\section{Results and discussion}

Kinetic studies for phenol sorption

The experimental data in adsorption are expressed in terms of the distribution ratio, $R_{\mathrm{d}}$, defined as the ratio of adsorbate concentration on solid phase to its concentration in liquid phase. The distribution ratio of adsorption is defined as:

$R_{\mathrm{d}}=\frac{[C]_{\text {solid }}}{[C]_{\text {liquid }}}$

Where $[C]_{\text {solid }}(\mathrm{mmol} / \mathrm{g})$ and $[C]_{\text {liquid }}(\mathrm{mmol} / \mathrm{mL})$ are the concentrations of species $C$ in the solid and liquid phases, respectively. At the beginning of the sorption step, $V(\mathrm{~mL})$ of solution with initial concentration $[C]^{\circ}(\mathrm{mmol} / \mathrm{mL})$ is used and at the end of the sorption step $V(\mathrm{~mL})$ of solution with concentration $[C]_{\text {liquid }}$ are present, hence the concentration of $C$ in the solid phase after sorption can be expressed as:

$[C]_{\text {solid }}=\frac{V\left([C]^{\circ}-[C]_{\text {liquid }}\right)}{W_{\text {solid }}}$

In terms of radioactivity, $[C]_{\text {liquid }}$ can be written as:

$[C]_{\text {liquid }}=\frac{A_{\text {liquid }}}{A^{\circ}}[C]^{\circ}$

From (1)-(3), the following equation is obtained:

$R_{\mathrm{d}}=\frac{V A^{\circ}-V A_{\text {liquid }}}{A_{\text {liquid }} W_{\text {solid }}}$

Where $A^{\circ}$ is the initial count rate of solution added for sorption (cps) $/ \mathrm{mL}, A_{\text {liquid }}$ is the count rate of solution after sorption (cps) $/ \mathrm{mL}, W_{\text {solid }}$ is the weight of solid material $(\mathrm{g})$ [15].

Phenol is an extremely harmful organic contaminant for which an intense research effort is being made to develop methods to remove it from environment. Phenol is an aromatic compound and its availability in solutions can be monitored by using a UV-Visible spectrophotometer which gives two broad bands with $\lambda_{\max }$ values 211 and $270 \mathrm{~nm}$ in water.

In our experiments, we tried to remove phenol from an aqueous solution onto a solid phase by using INaA (sodium form of insolubilized humic acid) as a sorbent. The results showed that phenol was not sorbed by INaA significantly, because negatively charged surface of INaA did not allow the sorption of polar phenol molecules. Therefore, surface of INaA was modified using a cationic surfactant (cetyltrimethylammoniumchloride) so that negatively charged

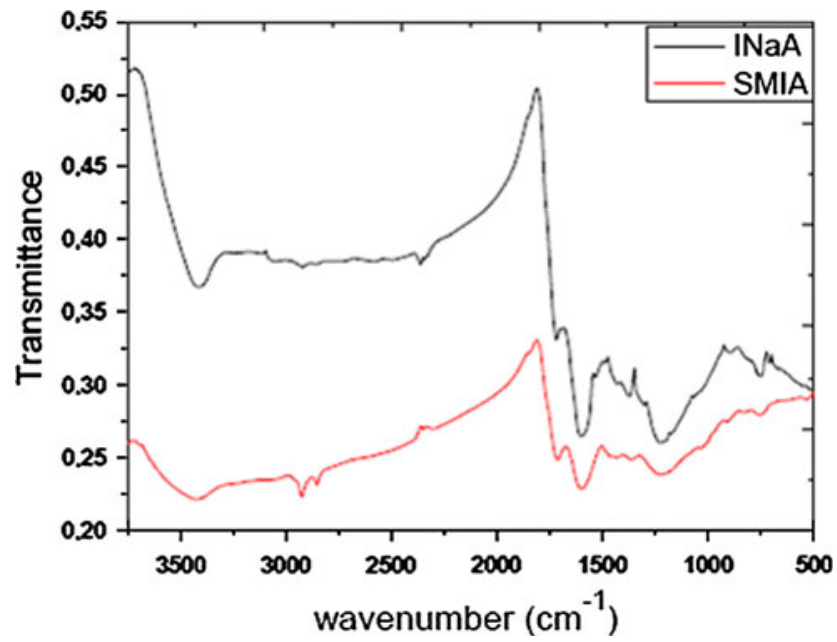

Fig. 1 FTIR spectra of sodium form of insolubilized humic acid (INaA) and surfactant modified insolubilized humic acid (SMIA)

surface were neutralized by cationic part of surfactant and phenol molecules were able to interact with highly hydrophobic (nonpolar) tails of surfactant molecules. It was found that cationic part of surfactant and negatively charged surface of INaA interacted strongly and alkyl peaks appeared at 2928 and $2857 \mathrm{~cm}^{-1}$ as shown in Fig. 1. The detailed analysis of infrared spectrum of INaA was given in our previous study [7].

To understand the kinetic behavior and determine the equilibrium time for phenol sorption onto surfactant modified insolubilized humic acid (SMIA), absorbance values of the remaining phenol in solution were measured at different shaking times ranging from 1 to $72 \mathrm{~h}$. The significant decrease at the absorbance values and kinetic data of phenol sorption are given in Table 1 .

Kinetic data clearly indicate the adsorption of phenol molecules onto the solid phase, SMIA. Equilibrium time of phenol removal was found to be $48 \mathrm{~h}$ and remained nearly constant thereafter as shown in Fig. 2. Phenol sorption was found to obey to the pseudo second order rate law [16] quite well Eqs. 5, 6 as shown in Fig. 3.

The rate law for such a system is expressed as:

$\frac{\mathrm{d} q}{\mathrm{dt}}=k_{2}\left(q_{\mathrm{e}}-q\right)^{2}$

where $q$ and $q_{\mathrm{e}}$ are the amount of solute sorbed per gram of sorbent at any time and at equilibrium, respectively, and $k_{2}$ is the pseudo second order rate constant of sorption. After integration and rearrangement of the above equation, the following equation is obtained with a linear form,

$\frac{t}{q}=\frac{1}{k_{2} q_{\mathrm{e}}^{2}}+\frac{1}{q_{\mathrm{e}}} t$

The plot of $t / q$ versus $t$ gives a straight line with slope of $1 / q_{\mathrm{e}}$ and intercept of $1 / k_{2} q_{\mathrm{e}}^{2}$. So the amount of cation 
Table 1 The kinetic data of phenol sorption onto surfactant modified insolubilized humic acid at different times at $25^{\circ} \mathrm{C}$

\begin{tabular}{lllll}
\hline $\begin{array}{l}\text { Time } \\
(\mathrm{min})\end{array}$ & Absorbance & $\begin{array}{l}{[\mathrm{Phenol}]_{\mathrm{s}}} \\
(\mathrm{mg} / \mathrm{g})\end{array}$ & $\begin{array}{l}{[\mathrm{Phenol}]_{\mathrm{liq}}} \\
(\mathrm{mg} / \mathrm{L})\end{array}$ & $\begin{array}{l}R_{\mathrm{d}} \\
(\mathrm{mL} / \mathrm{g})\end{array}$ \\
\hline 0 & 0.31578 & 0 & 20 & 0 \\
60 & 0.30662 & 0.101 & 19.49 & 5.18 \\
120 & 0.30412 & 0.133 & 19.34 & 6.86 \\
240 & 0.29372 & 0.264 & 18.68 & 14.15 \\
480 & 0.28116 & 0.423 & 17.88 & 23.67 \\
720 & 0.29164 & 0.290 & 18.55 & 15.67 \\
960 & 0.28135 & 0.421 & 17.90 & 23.52 \\
1200 & 0.26857 & 0.583 & 17.09 & 34.10 \\
1440 & 0.25520 & 0.752 & 16.24 & 46.30 \\
2220 & 0.25324 & 0.777 & 16.12 & 48.19 \\
2830 & 0.24483 & 0.883 & 15.58 & 56.67 \\
4320 & 0.24512 & 0.879 & 15.60 & 56.37 \\
A $270 \mathrm{~nm}$ & & & & \\
\hline
\end{tabular}

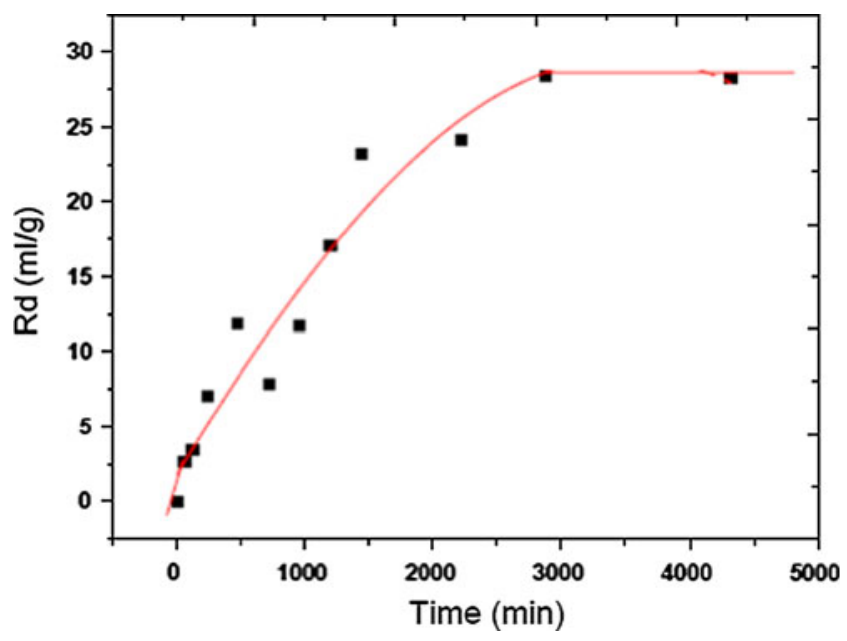

Fig. 2 Variation of $R_{\mathrm{d}}$ values with shaking time for phenol sorption onto surfactant modified insolubilized humic acid at $25{ }^{\circ} \mathrm{C}$

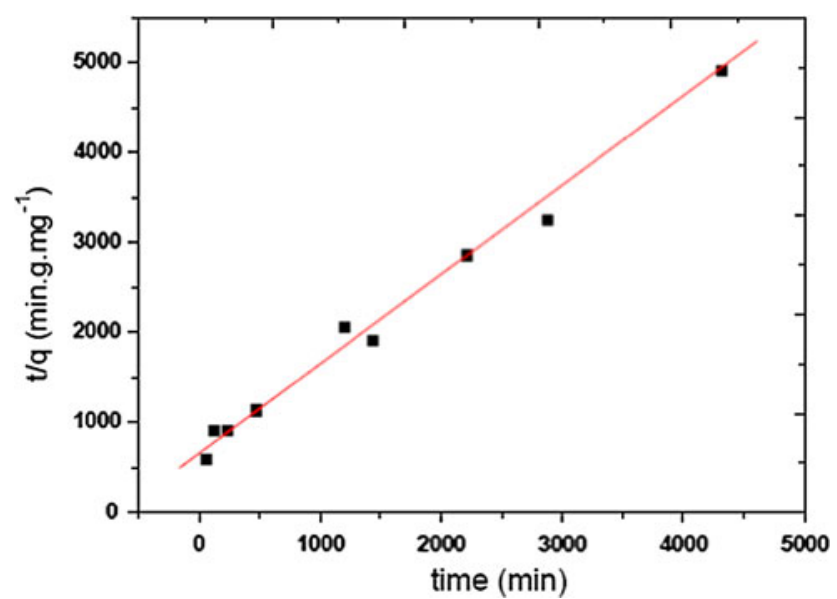

Fig. 3 Variation of $t / q$ values with shaking time for phenol sorption onto surfactant modified insolubilized humic acid at $25{ }^{\circ} \mathrm{C}$
Table 2 Amount of sorbed phenol per gram of sorbent, pseudo second order rate constant and correlation coefficient value for phenol sorption

\begin{tabular}{lllll}
\hline Sorbent & Sorbed substance & $q_{\mathrm{e}}(\mathrm{mg} / \mathrm{g})$ & $k_{2}\left(\mathrm{~g} \mathrm{mg}^{-1} \mathrm{~min}^{-1}\right)$ & $R^{2}$ \\
\hline SMIA & Phenol & 1.04 & $1.367 \times 10^{-3}$ & 0.99 \\
\hline
\end{tabular}

sorbed per gram of sorbent (INaA) at equilibrium $q_{\mathrm{e}}$ and sorption rate constant $k_{2}$ could be evaluated from the slope and intercept, respectively. Results are shown in Table 2.

Freundlich and Tempkin isotherms for phenol sorption

The data adequately obeyed Freundlich (Eq. 7) and Tempkin (Eq. 10) isotherms as shown in Figs. 4 and 5, respectively. The data of sorption is given in Table 3 .

Freundlich isotherm describes adsorption on solids possessing sites that might vary in their sorption energy, without any restriction on the sorption capacity of those solids [17]. The isotherm model is given by

$[C]_{\text {solid }}=k[C]_{\text {liquid }}^{n}$

Where $[C]_{\text {solid }}$ is the amount of ionic species adsorbed on the solid matrix at equilibrium $(\mathrm{mmol} / \mathrm{g}),[C]_{\text {liquid }}$ is the concentration of the cation in solution at equilibrium $(\mathrm{mmol} / \mathrm{mL}), k$ and $n$, are Freundlich constants.

This expression can be linearized as:

$\log [C]_{\text {solid }}=\log k+\log [C]_{\text {liquid }}$

Plotting $\log [C]_{\text {solid }}$ versus $\log [C]_{\text {liquid }}$ yields " $n$ " as the slope and "log $k$ " as the intercept.

The Freundlich constants " $n$ " and " $k$ " obtained at $25{ }^{\circ} \mathrm{C}$ are listed in Table 4. The Freundlich constant " $n$ " gives

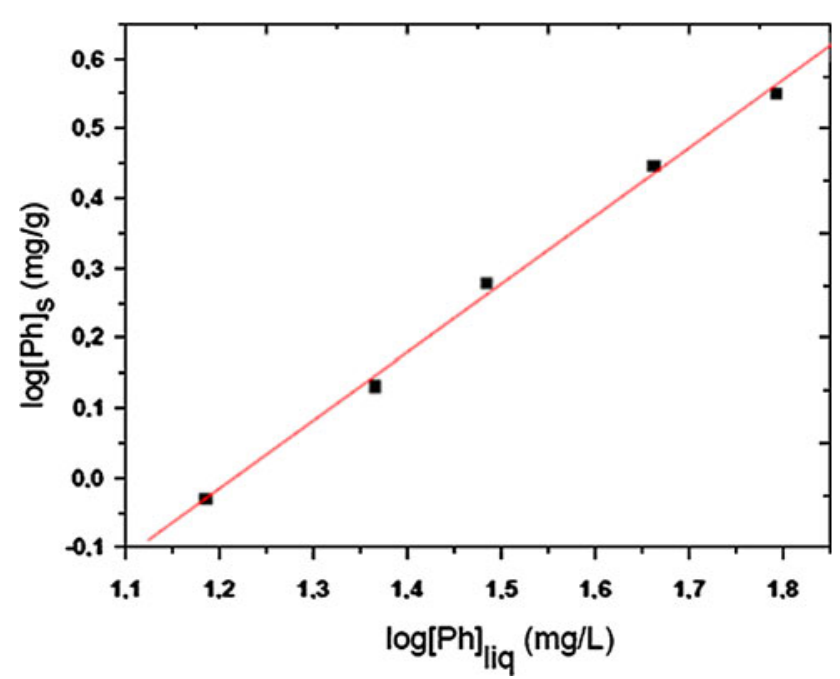

Fig. 4 Freundlich Isotherm plot for sorption of phenol onto surfactant modified insolubilized humic acid at $25{ }^{\circ} \mathrm{C}$ 


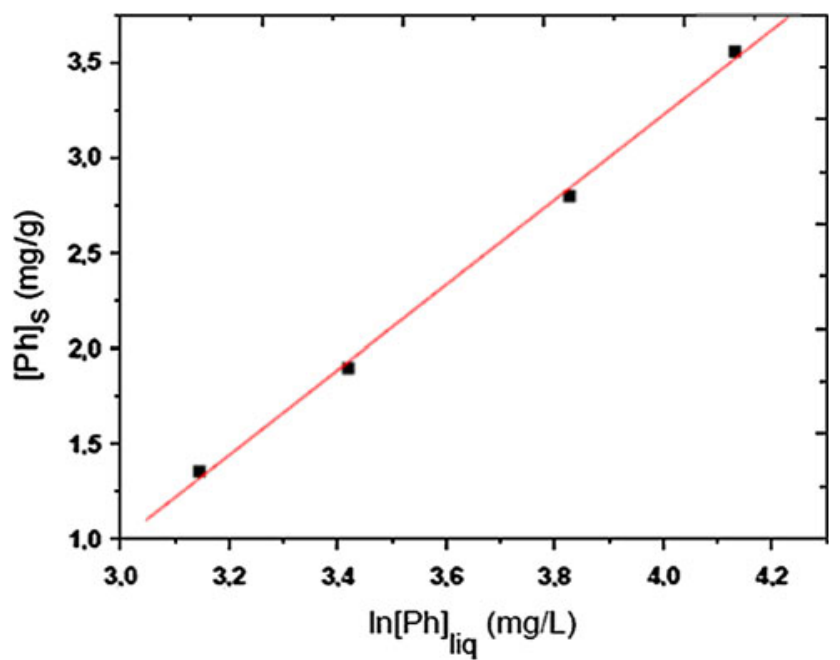

Fig. 5 Tempkin isotherm plot for sorption of phenol onto surfactant modified insolubilized humic acid at $25^{\circ} \mathrm{C}$

Table 3 The data of phenol sorption onto surfactant modified insolubilized humic acid at $25{ }^{\circ} \mathrm{C}$ and initial concentrations

\begin{tabular}{lllll}
\hline $\begin{array}{l}\text { Temperature } \\
(\mathrm{K})\end{array}$ & {$[C]^{\circ}(\mathrm{mg} / \mathrm{L})$} & $\begin{array}{l}R_{\mathrm{d}} \\
(\mathrm{mL} / \mathrm{g})\end{array}$ & $\begin{array}{l}{[\mathrm{Ph}]_{\mathrm{s}}} \\
(\mathrm{mg} / \mathrm{g})\end{array}$ & $\begin{array}{l}{[\mathrm{Ph}]_{\text {liq }}} \\
(\mathrm{mg} / \mathrm{L})\end{array}$ \\
\hline 298 & 20 & 60.89 & 0.93 & 15.33 \\
298 & 30 & 58.22 & 1.35 & 23.24 \\
298 & 40 & 62.04 & 1.89 & 30.53 \\
298 & 60 & 60.83 & 2.80 & 46.01 \\
298 & 80 & 57.10 & 3.55 & 62.23 \\
\hline
\end{tabular}

Table 4 Freundlich constants, $n$ and $k$, obtained from the least square fits of the sorption data of phenol onto surfactant modified insolubilized humic acid

\begin{tabular}{lll}
\hline Sorbed organic & Freundlich constant & \\
\hline Phenol & $n$ & 0.9746 \\
& $k$ & 0.0653
\end{tabular}

The Linear Correlation Coefficient is greater than 0.9965

information about surface heterogeneity. Since the linearity of sorption increases as " $n$ " approaches unity, SMIA shows a very high affinity for phenol molecules. Sorption affinity " $k$ " values of phenol sorption onto SMIA are higher than the sorption affinity values of phenol sorption onto surfactant modified natural zeolites studied in the literature [18] under same conditions.

Tempkin isotherm includes the effects of some indirect adsorbate/adsorbate interactions on adsorption isotherms and suggested that because of these interactions the heat of adsorption of all the molecules in the layer would decrease linearly with coverage.
Table 5 Tempkin isotherm constants, $K(\mathrm{~L} / \mathrm{mg}), B$ and $b(\mathrm{~kJ} / \mathrm{mol})$ obtained from the least square fits of the sorption data of phenol onto surfactant modified insolubilized humic acid

\begin{tabular}{lll}
\hline Sorbed organic & Tempkin constant & \\
\hline Phenol & $K$ & 0.0776 \\
& $B$ & 2.2316 \\
& $b$ & 1.110
\end{tabular}

The Linear Correlation Coefficient is greater than 0.998

The Tempkin isotherm has been used in the following form:

$[\mathrm{Ph}]_{s}=\frac{R T}{b}\left(\ln K[\mathrm{Ph}]_{1}\right)$

Equation 9 can be expressed in its linear form as;

$[\mathrm{Ph}]_{\mathrm{s}}=B \ln K+B \ln [\mathrm{Ph}]_{1}$

where

$B=\frac{R T}{b}$

The adsorption data can be analyzed according to Eq. 10 . A plot of $[\mathrm{Ph}]_{\mathrm{s}}$ (amount of phenol adsorbed onto SMIA at equilibrium, $\mathrm{mg} / \mathrm{g}$ ) versus $\ln [\mathrm{Ph}]_{1}$ (the concentration of phenol in solution at equilibrium, $\mathrm{mmol} / \mathrm{mL}$ ) enables the determination of the constants " $K$ ", " $B$ " and " $b$ ". The constant " $B$ " is related to the heat of adsorption [19]. " $K$ " is the equilibrium binding constant $(1 / \mathrm{mg})$ corresponding to the maximum binding energy and " $b$ " is the heat of adsorption. The Tempkin isotherm constants are listed in Table 5. The positive heat of adsorption shows that the sorption process exhibits endothermic behavior. The equilibrium constant value corresponds to negative Gibbs Free Energy change, $\Delta G^{\circ}$, therefore sorption process is spontaneous and favors the products.

Sorption studies of cesium onto surfactant modified insolubilized humic acid

Dubinin-Radushkevich isotherm described well the sorption data of cesium sorption onto SMIA as shown in Fig. 6 and Table 6.

The D-R isotherm model [20] is valid at low concentration ranges and can be used to describe sorption on both homogeneous and heterogeneous surfaces. It can be represented by the general expression:

$[C]_{\text {solid }}=[C]_{\mathrm{m}} \exp -\left(K \varepsilon^{2}\right)$

where $\varepsilon$, Polanyi potential; RT $\times \ln \left(1+\frac{1}{C_{\text {liquid }}}\right) ; C_{\text {liquid }}$, solute equilibrium constant in solution $(\mathrm{mmol} / \mathrm{mL}) ; R$, ideal gas constant $\left(8.3145 \mathrm{~J} \mathrm{~mol}^{-1} \mathrm{~K}^{-1}\right) ; T$, absolute 


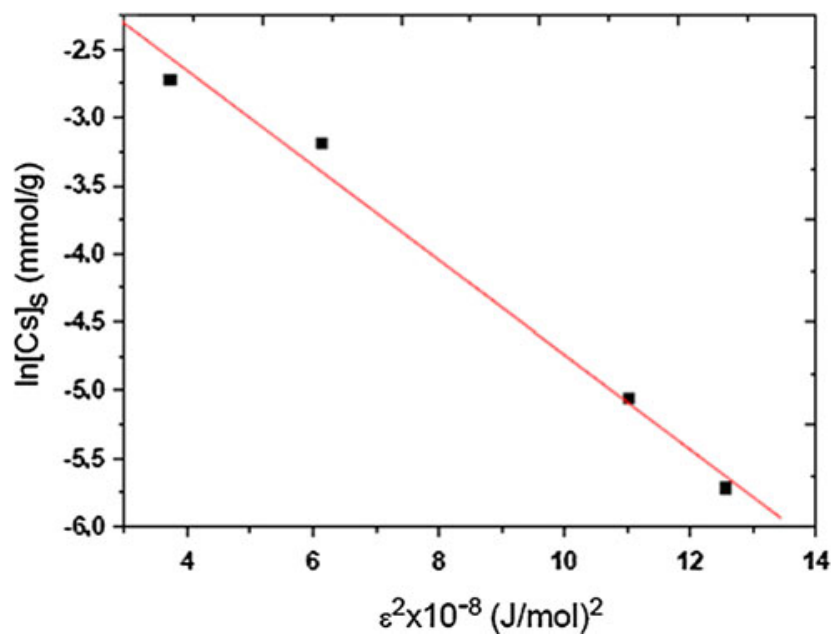

Fig. 6 Dubinin-Raduskevich isotherm plot for sorption of $\mathrm{Cs}^{+}$onto surfactant modified insolubilized humic acid at $25{ }^{\circ} \mathrm{C}$

Table 6 The D-R isotherm constants, $K(\mathrm{~mol} / \mathrm{kJ})^{2}, C_{\mathrm{m}}(\mathrm{mmol} /$ $100 \mathrm{~g}$ ), and $E(\mathrm{~kJ} / \mathrm{mol})$ obtained from the least square fits for the sorption data of $\mathrm{Cs}^{+}$on surfactant modified insolubilized humic acid

\begin{tabular}{lll}
\hline Sorbed ion & D-R constant & \\
\hline Cs + & $C_{\mathrm{m}}$ & 28.134 \\
& $K$ & $3.473 \times 10^{-3}$ \\
& $E$ & 12.0
\end{tabular}

The Linear Correlation Coefficient is greater than 0.9872

temperature $(\mathrm{K}) ;[C]_{\mathrm{m}}$, sorption capacity of sorbent per unit weight $(\mathrm{mmol} / \mathrm{g}) ; K$, constant related to the energy of sorption; $[C]_{\text {solid, }}$ amount of solute sorbed per unit weight $(\mathrm{mmol} / \mathrm{g})$.

The linear form of the equation above can be obtained by rearranging it to give:

$\ln C_{\text {solid }}=\ln C_{\mathrm{m}}-K \varepsilon^{2}$

If $\ln C_{\text {solid }}$ is plotted against $\varepsilon^{2}, K$ and $\ln C_{\mathrm{m}}$ will be obtained from the slope and the intercept, respectively. The value of $K(\mathrm{~mol} / \mathrm{kJ})^{2}$ is related to the adsorption mean free energy, $E(\mathrm{~kJ} / \mathrm{mol})$, defined as the free energy change required to transfer one mole of ions from infinity in solution to the solid surface. The adsorption mean free energy $E$ is given as:

$E=(2 K)^{-1 / 2}$

The cation exchange capacity $\left(C_{\mathrm{m}}\right)$ for cesium sorption onto SMIA is 2.5 times less than the $C_{\mathrm{m}}$ value for cesium sorption onto INaA [7]. Surfactant molecules occupied most of the negatively charged functional groups on INaA, therefore $C_{\mathrm{m}}$ value decreased in the case of cesium sorption onto SMIA. Adsorption mean free energy value (Table 6)

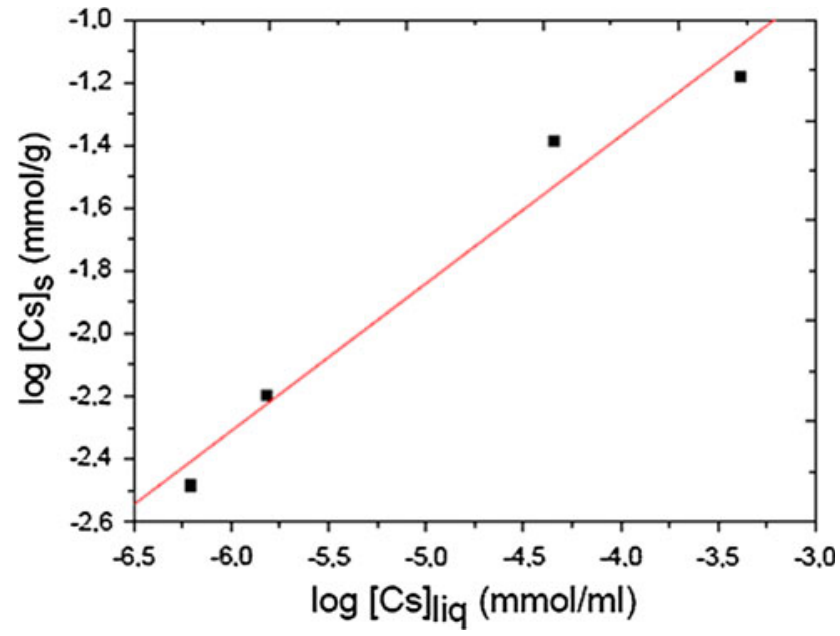

Fig. 7 Freundlich isotherm plots for sorption of $\mathrm{Cs}^{+}$onto surfactant modified insolubilized humic acid at $25{ }^{\circ} \mathrm{C}$

Table 7 Freundlich constants, $n$ and $k$, obtained from the least square fits of the sorption data of $\mathrm{Cs}^{+}$onto surfactant modified insolubilized humic acid

\begin{tabular}{lll}
\hline Sorbed cation & Freundlich constant & \\
\hline $\mathrm{Cs}^{+}$ & $n$ & 0.4695 \\
& $k$ & 3.217 \\
\hline
\end{tabular}

indicates that sorption process is an ion-exchange type of sorption [21]. The exchanged ions are sodium ions remaining on the surface after surfactant modification.

The Freundlich isotherm also describes well the sorption data of cesium sorption onto SMIA (Fig. 7). The Freundlich constants " $n$ " and " $k$ " obtained at $25{ }^{\circ} \mathrm{C}$ are listed in Table 7. The results are similar with the " $n$ " and " $k$ " values obtained in the case of cesium sorption onto INaA [7]. This shows that surfactant modification does not make a significant change on the sorption energy barrier and linearity of cesium sorption. The decrease upon the uptake of cesium ions is only the result of the decreasing number of negatively charged surface functional groups.

\section{Conclusion}

Surfactant modified insolubilized humic acid can be used as an effective sorbent for the removal of both phenolic substances and toxic cations from aquatic environment. It is easy and cheap to produce. Equilibrium for phenol sorption onto SMIA was achieved within $48 \mathrm{~h}$. Negatively charged surface of sodium form of insolubilized humic was readily modified with a cationic surfactant (cetyltrimethylammonium chloride) and structural changes (attachment 
of alkyl groups to the surface) during surfactant modification were elucidated utilizing FTIR spectroscopic technique. Kinetic studies indicated that adsorption behavior of phenol obey pseudo second order rate law. Cation sorption data have been interpreted in terms of Freundlich and Dubinin-Radushkevich equations. Phenol sorption data was described well by both Tempkin and Freundlich isotherms.

Acknowledgements The authors would like to gratefully thank to Ankara University Soil Science department for providing humic acid samples, Dr. Umit Akbey at Max Planck Institute (polymer division, Mainz) for his helps to characterize insolubilized humic acid and Bilkent University for financial support.

\section{References}

1. Dabrowski A, Podkoscielny P, Hubicki Z, Barczak M (2005) Adsorption of phenolic compounds by activated carbon-a critical review. Chemosphere 58:1049-1070

2. Ahmaruzzaman Md (2008) Adsorption of phenolic compounds on low-cost adsorbents. A review. Adv Colloid Interface Sci 143:48-67

3. Busca G, Berardinelli S, Resini C, Arrighi L (2008) Technologies for the removal of phenol from fluid streams: a short review of recent developments. J Hazard Mater 160:265-288

4. Sathishkumar M, Binupriya AR, Kavitha D, Selvakumar R, Jayabalan R, Choi JG, Yun SE (2009) Adsorption potential of maize cob carbon for 2, 4-dichlorophenol removal from aqueous solutions: equilibrium, kinetics and thermodynamics modeling. Chem Eng J 147:265-271

5. Shahwan T, Erten HN (2002) Thermodynamic parameters of $\mathrm{Cs}^{+}$ sorption on natural clays. J Radioanal Nucl Chem 253(1):115120

6. Seki H, Suzuki A (1995) Adsorption of heavy metal ions onto insolubilized humic acid. J Colloid Interface Sci 171:490-494

7. Celebi O, Kilikli A, Erten HN (2009) Sorption of radioactive cesium and barium ions onto solid humic acid. J Hazard Mater 168:695-703
8. Gezici O, Kara H, Ersöz M, Abali Y (2005) The sorption behavior of a nickel insolubilized humic acid system in a column arrangement. J Colloid Interface Sci 292:381-391

9. Baker H, Khalili F (2004) Analysis of the removal of lead(II) from aqueous solutions by adsorption onto insolubilized humic acid: temperature and $\mathrm{pH}$ dependence. Anal Chim Acta 516:179_ 186

10. El-Eswed B, Khalili F (2006) Adsorption of $\mathrm{Cu}(\mathrm{II})$ and $\mathrm{Ni}(\mathrm{II})$ on solid humic acid from the Azraq area, Jordan. J Colloid Interface Sci 299:497-503

11. Gezici O, Kara H, Ayar A, Topkafa M (2007) Sorption behavior of $\mathrm{Cu}$ (II) ions on insolubilized humic acid under acidic conditions: an application of Scatchard plot analysis in evaluating the $\mathrm{pH}$ dependence of specific and nonspecific bindings. Sep Purif Technol 55:132-139

12. Gezici O, Kara H, Yanık S, Ayyildiz HF, Kucukkolbasi S (2007) Investigating sorption characteristics of copper ions onto insolubilized humic acid by using a continuously monitored solid phase extraction technique. Colloids Surf A Physicochem Eng Asp 298:129-138

13. Baker H, Abdel-Halim HM (2007) Removal of nickel ions from aqueous solutions by using insolubilized humic acid: effect of $\mathrm{pH}$ and temperature. Asian J Chem 19:233-245

14. Weber T, Allard T, Benedetti MF (2006) Iron speciation in interaction with organic matter: modelling and experimental approach. J Geochem Explor 88:166

15. Shahwan T, Suzer S, Erten HN (1998) Sorption Studies of $\mathrm{Cs}^{+}$ and $\mathrm{Ba}^{2+}$ Cations on Magnesite. Appl Radiat Isot 49:915-921

16. Azizian S (2004) Kinetic models of sorption: a theoretical analysis. J Colloid Interface Sci 276:47-52

17. Shahwan T, Erten HN, Unugur S (2006) A characterization study of some aspects of the adsorption of aqueous $\mathrm{Co}^{2+}$ ions on a natural bentonite clay. J Colloid Interface Sci 300:447-452

18. Kuleyin A (2007) Removal of phenol and 4-chlorophenol by surfactant-modified natural zeolite. J Hazard Mater 144:307-315

19. Allen SJ, Mckay G, Porter JF (2004) Adsorption isotherm models for basic dye adsorption by peat in single and binary component systems. J Colloid Interface Sci 280:322-333

20. Shahwan T, Erten HN (2004) Temperature effects in barium sorption on natural kaolinite and chlorite-illite clays. J Radioanal Nucl Chem 260:43-48

21. Shahwan T (2000) Ph.D. Thesis. Department of Chemistry, Bilkent University 